\title{
Pleiotropic Chemotherapy to Abrogate Glioblastoma Multiforme Migration/Invasion
}

\author{
LAWRENCE HELSON $^{1}$ and MUHAMMED MAJEED ${ }^{2}$ \\ ${ }^{1}$ Consultant, Sabinsa Corporation, East Windsor, NJ, U.S.A.; \\ ${ }^{2}$ Sabinsa Corporation, East Windsor, NJ, U.S.A.
}

\begin{abstract}
Current clinical failure to cure primary glioblastoma multiforme in virtually all adult patients is due to genetic aberrations, molecular heterogeneity, and clonal evolution of tumor stem and differentiated cells within the core tumor, leading to their migration, invasion and proliferation in normal surrounding and in distant cerebral tissue sites. These factors are the causes of targeted drug resistance, inadequate surgical removal, and inadequate radio-therapeutic interventions. Resolution of this clinical conundrum may be found in administration of Withaferin A alone or in combination with pleiotropic drugs which address aberrant molecules and pathways promoting tumor cell motility, migration, invasion and proliferation.
\end{abstract}

Primary glioblastoma multiforme (PGM) is a common migratory, invasive heterogeneous malignant brain tumor in adults with a median survival of 14.6 months, following surgical ablation, radiotherapy and targeted chemotherapy (1). The current clinical failure to completely cure this tumor is due to several factors: the core tumor is composed of both tumor stem cells and differentiated tumor cells with differing genotypic and phenotypic characteristics promoting cellular motility, migration and invasion. Proteolytic digestion of the surrounding normal cerebral tissues also permits invasion and proliferation of tumor at distant sites in the brain (2).

The tumor cell heterogeneity with multiple molecular pathway alterations, genetic changes and clonal evolution promoting motility, migration and invasion, is the result of deregulated tumor genomes. Detailed analysis of PGM has revealed deletion of tumor suppressor genes, receptor tyrosine kinase amplifications and mutational aberrations,

Correspondence to: Lawrence Helson, Sabinsa Corporation, East Windsor, NJ, U.S.A. Tel: +1 2155389996, e-mail: lhelson@comcast.net

Key Words: Glioblastoma multiforme, motility, migration, invasion, proliferation, pleiotropic drugs, withaferin A, review. characterized by augmented survival pathways, defects in the apoptosis signaling machine and most important, a propensity to migration and invasion (1).

To improve outcomes in patients with glioblastoma multiforme, a therapeutic approach addressing clonal evolution, cellular heterogeneity, a plethora of mutations, and altered molecular pathways is required. Treatment capable of inhibiting tumor growth, motility, migration and invasion ultimately may prevent the development of recurrent tumors. Single targeting drugs, such as temozolamide, does not address all these issues, indicating a need for a novel medicinal compound or a combination of pleiotropic drugs (3).

There are several drugs, which, in pre-clinical studies, have shown that they inhibit molecular components promoting motility, migration, invasion, and proliferation at invaded sites, causing tumor recurrence (Tables I and II). Among natural products, withanolide extracts have been extensively studied in pre-clinical in vitro studies and in animal models of neural tumors (4).

\section{Withanolides}

Withanolides are naturally-occurring $\mathrm{C}_{28}$ steroidal lactones built on an ergostane framework, in which $\mathrm{C}_{22}$ and $\mathrm{C}_{26}$ are oxidized to form a six-member lactone ring. Withanolides are a potential drug source accommodating pleiotropic requirements. The most active pleiotropic drug of this class is withaferin $\mathrm{A}$, a major constituent of Withania somnifera. This natural product has a wide range of pharmacological properties, including cardioprotective, anti-inflammatory, immuno-modulatory, anti-lactone, and anti-angiogenic activities (5). Withaferin A is a 4-hydroxy steroid, an enone, an epoxide, an ergostanoid, and a secondary alcohol. It has $\alpha, \beta$-unsaturated carbonyl moieties, permitting it to act as a Michael acceptor and a thiol modifier which contribute to its pleiotrophic interactions with glioblastomaspecific migration/invasive biochemical processes (6).

These interactions serve as the mechanistic basis for its anti-tumoral properties, prohibiting tumor cell motility, and 
Table I. Drugs inhibiting migration/invasion of glioblastoma cells.

\begin{tabular}{|c|c|c|}
\hline Drug & Activity & Ref \\
\hline $\begin{array}{l}\text { Sunitinib and } \\
\text { Lapatinib }\end{array}$ & $\begin{array}{l}\text { Anti-VEGFR (sunitinib) and anti-EGFR multi-targeted agent (lapatinib), applied either alone or in combination, } \\
\text { affect the migration capacity of glioblastoma cell lines. The dual anti-EGFR/HER-2 agent, lapatinib } \\
\text { and the multi-targeted agent, sunitinib inhibit glioblastoma cell migration, through interruption of growth factor } \\
\text { receptor integrin complexes formation. Sunitinib affects the VEGFR-integrin } \beta(3) \text { and PDGFR-integrin } \beta(3) \\
\text { complexes formation. At } 10 \mu \mathrm{M} \text {, Sunitinib-induced an anti-proliferative and anti-apoptotic effects on glioblastoma } \\
\text { cells. The invasion of these cells implanted into brain was decreased by } 49 \%(p<0.001) \text {. Treatment was } \\
\text { also associated with decrease in phosphorylation of Src }(35 \%) \text { and focal adhesion kinase }(44 \%) \text {. } \\
\text { Lapatinib (anti-EGFR) affects the formation of EGFR-integrin } \beta(1) \text { complex. }\end{array}$ & $(16,17)$ \\
\hline KU-60019 & $\begin{array}{l}\text { This is an A-T mutated kinase-specific inhibitor which inhibits glioblastoma motility and invasion, } \\
\text { by acting on AKT and MEK/ERK pro-survival signaling pathways. With an } \mathrm{IC}_{50} \text { value of } 6.3 \mathrm{nM} \text {, } \\
\text { KU-60019 is also a potent inhibitor of ATM (ataxia telangiectasia mutated) kinase, a member of the } \\
\text { phosphatidylinositol-3-kinase-related kinase family that is critical in regulating cell cycle checkpoints } \\
\text { and DNA repair. Further, KU-60019 radiosensitizes U1242 human glioma cells, and also } \\
\text { blocks U1242 cell migration and invasion through matrigel. }\end{array}$ & $(18)$ \\
\hline Dexamethasone & $\begin{array}{l}\text { Glioblastoma induced brain oedema and inflammation have been widely treated with } \\
\text { dexamethasone, which also inhibits glioblastoma cell proliferation and migration. }\end{array}$ & $(19)$ \\
\hline Temozolomide & Glioblastoma multiforme tumors rapidly develop resistance to this drug. Withaferin & $(15)$ \\
\hline$(\mathrm{TMZ})$ & $\begin{array}{l}\text { A exhibits effects against TMZ-resistant tumors glioblastoma multiforme cells as a monotherapy } \\
\text { and in combination with TMZ. It prevents cell proliferation by dose-dependent } \mathrm{G}_{2} / \mathrm{M} \text { cell cycle arrest } \\
\text { and cell death through both intrinsic and extrinsic apoptotic pathways with depletion of principle } \\
\text { proteins of the Akt/mTOR and MAPK survival and proliferation pathways, and with diminished } \\
\text { phosphorylation of Akt, mTOR, and p70 S6K but compensatory activation of ERK1/2. Depletion of } \\
\text { tyrosine kinase cell surface receptors c-Met, EGFR, and Her2 is also observed. Withaferin A induces of } \\
\text { N-acetyl-L-cysteine-repressible oxidative stress directly and through a subsequent heat shock response } \\
\text { with HSP32 and HSP70 up-regulation and decreased HSF1. Pretreatment of TMZ-resistant } \\
\text { glioblastoma cells induces } O^{6} \text {-methylguanine-DNA methyltransferase (MGMT) depletion which } \\
\text { potentiates TMZ-mediated MGMT degradation. Combination treatment with } \\
\text { both drugs yields resensitization of MGMT-mediated TMZ-resistance. }\end{array}$ & \\
\hline Cediranib & $\begin{array}{l}\text { This drug has cytostatic and cytotoxic effects and antiangiogenic activity in vivo, } \\
\text { and inhibits mitogen-activated protein kinase (MAPK) and AKT pathways. }\end{array}$ & (20) \\
\hline
\end{tabular}

Table II. Drugs promoting migration/invasion of glioblastoma cells.

\begin{tabular}{lc}
\hline Drug & Activity \\
\hline $\begin{array}{l}\text { Imatinib and } \\
\text { nilotinib }\end{array}$ & $\begin{array}{c}\text { Treatment of human glioblastoma multiforme (GBM) tumour cells with imatinib and the } \\
\text { closely-related drug, nilotinib increases tyrosine phosphorylation of p130Cas, focal adhesion kinase (FAK) } \\
\text { and the downstream adaptor protein paxillin (PXN), resulting in enhanced cell migration and invasion. } \\
\text { Systemic anti-angiogenic therapy can increase the invasiveness of gliomas in the orthotopic } \\
\text { model leading to gliomatosis cerebri. Tumor cell invasion was tightly associated with preexistent } \\
\text { blood vessels, suggesting that increased cooption of the host vasculature could represent a } \\
\text { compensatory mechanism that is selected for by inhibiting adequate tumor vascularization. }\end{array}$ \\
\hline
\end{tabular}

migratory/invasive characteristics, wherein the tumor cells to leave the primary site and invade normal brain parenchyma. The inhibition of glioblastoma growth, migration and invasion into normal cerebral tissue translates into control of tumor dispersal (6). Withaferin A modulates several oncogenic targets simultaneously (7). It induces cell cycle arrest and apoptosis in glioma cells $(8,9)$. In U 87 human glioblastoma cell line, the $50 \%$ inhibition concentration ( $\mathrm{IC}_{50}$ ) was found to be $1.4 \mu \mathrm{g} / \mathrm{mL}$, equivalent to $2.97 \mu \mathrm{M}$
(Figure 1, unpublished observation, Sabinsa corporation). Withaferin A was also found to induce apoptosis in glioblastoma cells, which was evident within 24 hours of treatment. The number of total apoptotic cells increased from $7.2 \%$ to $28.1 \%$ in treated cells (Figure 1, unpublished observation, Sabinsa corporation).

Withaferin A is purified from Withania somnifera and formulated in capsules containing $10 \mathrm{mg}$ of active compound (10). Withaferin A is reported to have an oral bioavailability of 
Table III. Inhibiting effects of Withaferin A on putative targets leading to inhibition of migration invasion and proliferation of glioblastoma cells.

\begin{tabular}{lr}
\hline Putative targets & Reference \\
\hline Intermediate filament protein protein-vimentin & $(24)$ \\
Cyclin B1, Cdks, survivin & $(25)$ \\
AMPKa & $(25)$ \\
Tuberin/TSC2 tumor suppressor & $(25)$ \\
HSP70, HSP32, HSP2 & $(25)$ \\
Extracellular pro-apoptotic tumor suppressor protein, Par-4 & $(26)$ \\
Cell surface GRP78 & $(26)$ \\
Antioxidant-iSOD, HO-1, GST, NQO1, GPx-1, and Nrf2 & $(27)$ \\
Apoptosis by cleaved PARP, activation of caspase-9, 3, 8, MAPK pathway Bax, Bak, DR5, p21, p53, Annexin-A2 & $(25)$ \\
HSF1 & $(25,27)$ \\
NFkB & $(27)$ \\
VEGF, CD31, CD321, MMP-2, MMP-9, ERK, SP1, Notch 1, Akt, EGFR, HER2, IKKbeta, & \\
PCNA, iNOS, PGE2, Cox-2, IL-6, IL-1 1 , JNK, pERK, STAT- 3 & $(29)$ \\
Apoptosis regulatory protein (CARP)-1/CCAR-1 & \\
\hline
\end{tabular}

$32.4 \pm 4.8 \%$, resulting in approximately $1.25 \mu \mathrm{M}$ concentration in the blood $(11,12)$. The $\mathrm{T}_{\max }$ of $\mathrm{W}$. somnifera extract having $0.045 \%$ withaferin A was 20 min and the T1/2 was found to be $59.9 \pm 15.9 \mathrm{~min}$, while purified withaferin A showed a higher half-life of $7.6 \pm 3.3 \mathrm{~h}(13,14)$. Considering these PK parameters in rodents, $10 \mathrm{mg}$ dose of withaferin A is likely to achieve the therapeutic dose in human in order to have a biological effect.

\section{Mechanistic Targets of Migration-invasion and Interacting Drugs}

Administration of withaferin A, a polyploidic compound as an oral anti-migration/invasion agent for patients with glioblastoma requires several characteristics to be proved as clinically safe and effective. Assessment of the oral bioavailability of Withaferin $\mathrm{A}$ is important since the intestinal flora and epithelium may have a role in the absorption, transportation and possible inactivation of this drug. There is published pre-clinical evidence that ingestion of oral Withaferin A results in a high concentration in the plasma (4). The effect of withaferin A on molecules and pathways inhibiting migration, invasion, and proliferation of glioblastoma multiforme are given in Tables III and IV.

\section{Discussion}

Failure to improve the outcomes of contemporary treatment of glioblastoma multiforme is due to its migratory and invasive characteristics, enhanced by a number of genetic mutations in both tumor stem and differentiated cells compounded by clonal evolution, and a plethora of heterogeneous molecules and pathways promoting cellular motility, migration, invasion and growth in normal cerebral tissues proximal to and at distance from the core tumor.
Table IV. Effect of Withaferin A on inhibition of migration, invasion and proliferation glioblastoma cells.

\begin{tabular}{lc}
\hline Molecular pathway & Reference \\
\hline Angiogenesis & $(5)$ \\
Cell proliferation & $(25)$ \\
pAkt signaling pathway & $(25)$ \\
Invasiveness of glioblastoma stem cells & $(27)$ \\
Tumor cell metabolism & $(27)$ \\
Spindle tubule organization & $(27)$ \\
Inflammation & $(27)$ \\
\hline
\end{tabular}

Due to the limitations of curative surgery, radiotherapy, and targeted chemotherapy, addressing this problem requires application of one or a combination of pleiotropic drugs prior to or concomitant with surgery and radiotherapy. It is suggested, that the drug Withaferin A, can be applied in combination with other drugs, such as sutinib, lapatinib, KU60019, dexamethasone, cedarinib, and temozolamide to inhibit migration/invasion of glioblastoma cell lines $(14,15)$.

\section{Conflicts of Interest}

LH has no financial involvement with Sabinsa Inc. MM is Founder and Managing Director of Sami Labs Limited and Sabinsa Corporation, which manufactures withaferin A for potential human trials.

\section{Authors' Contributions}

LH wrote and conceived the study. MM and scientists in Sami Labs, India performed the in vitro studies of Withaferin A. 
A

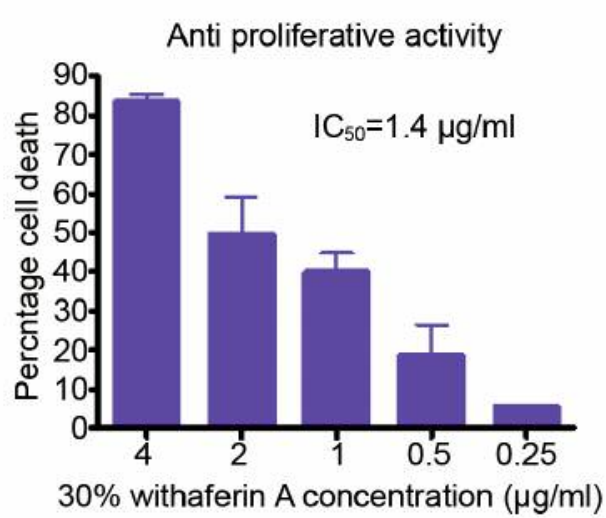

B

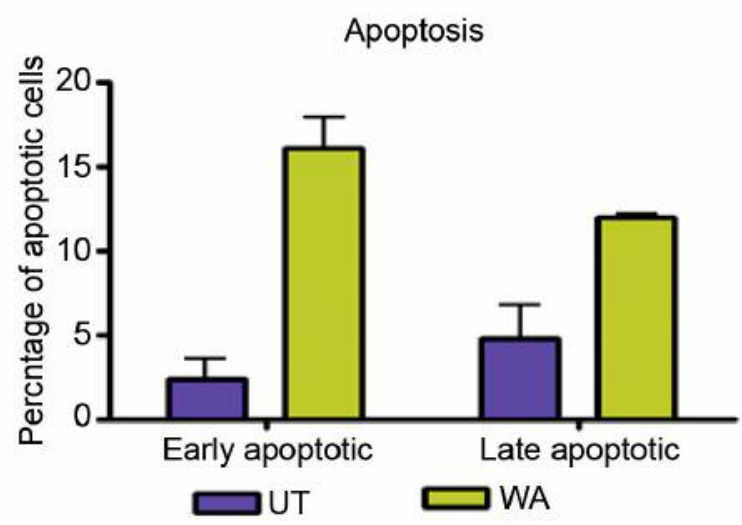

$30 \%$ withaferin $\mathrm{A}(1.4 \mu \mathrm{g} / \mathrm{ml})$

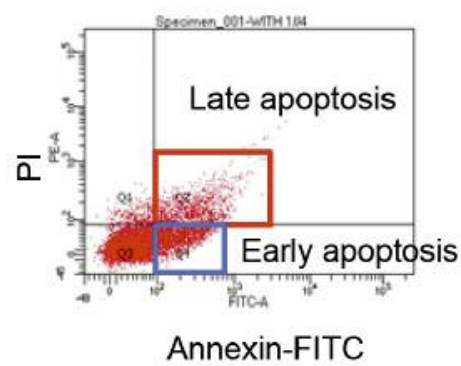

Figure 1. Anti-proliferative and apoptotic activity of 30\% withaferin A in glioblastoma cells (U97MG). The anticancer activity of $30 \%$ withaferin A was assessed in glioblastoma cells (U97MG) in vitro by MTT assay. Glioblastoma cells were treated with $1.4 \mu \mathrm{g} / \mathrm{mL}$ (IC $\mathrm{C}_{50}$ concentration) of $30 \%$ withaferin A for 48 hours and apoptosis was studied by flow cytometry using annexin - FITC and propidium iodide (PI) staining. Annexin positive cells were considered to be in early apoptosis while double positive cells (annexin + PI) were late apoptotic cells. UT: Untreated, WA: $30 \%$ withaferin A.

\section{References}

1 Touat M, Idbaih A, Sanson M and Ligon KL: Glioblastoma targeted therapy: Updated approaches from recent biological insights. Ann Oncol 28(7): 1457-1472, 2017. PMID: 28863449. DOI: $10.1093 /$ annonc/mdx 106

2 Johnson DR and O'Neill BP: Glioblastoma survival in the united states before and during the temozolomide era. J Neurooncol 107(2): 359-364, 2012. PMID: 22045118. DOI: 10.1007/s11060011-0749-4

3 Lee CY: Strategies of temozolomide in future glioblastoma treatment. Onco Targets Ther 10: 265-270, 2017. PMID: 28123308. DOI: $10.2147 /$ OTT.S120662

4 Subramanian C, Grogan PT, Opipari VP, Timmermann BN and Cohen MS: Novel natural withanolides induce apoptosis and inhibit migration of neuroblastoma cells through down regulation of n-myc and suppression of akt/mtor/nf-kappab activation. Oncotarget 9(18): 14509-14523, 2018. PMID: 29581860. DOI: 10.18632 /oncotarget.24429
5 Mohan R, Hammers HJ, Bargagna-Mohan P, Zhan XH, Herbstritt CJ, Ruiz A, Zhang L, Hanson AD, Conner BP, Rougas $\mathrm{J}$ and Pribluda VS: Withaferin $\mathrm{a}$ is a potent inhibitor of angiogenesis. Angiogenesis 7(2): 115-122, 2004. PMID: 15516832. DOI: $10.1007 / \mathrm{s} 10456-004-1026-3$

6 Furnari FB, Fenton T, Bachoo RM, Mukasa A, Stommel JM, Stegh A, Hahn WC, Ligon KL, Louis DN, Brennan C, Chin L, DePinho RA and Cavenee WK: Malignant astrocytic glioma: Genetics, biology, and paths to treatment. Genes Dev 21(21): 2683-2710, 2007. PMID: 17974913. DOI: 10.1101/gad. 1596707

7 Shah N, Kataria H, Kaul SC, Ishii T, Kaur G and Wadhwa R: Effect of the alcoholic extract of ashwagandha leaves and its components on proliferation, migration, and differentiation of glioblastoma cells: Combinational approach for enhanced differentiation. Cancer Sci 100(9): 1740-1747, 2009. PMID: 19575749. DOI: 10.1111/j.1349-7006.2009.01236.x

8 Grogan P, Samadi AK and Cohen MS: A novel cytotoxic agent induces apoptosis in malignant gliomas in vitro. J Surg Res 158: 341-342, 2010. PMID: 23129310. DOI: 10.1016/j.jss.2009. 11.468 
9 Grogan PT, Sleder KD, Stecklein SR and Cohen MS: Vassobia breviflora root-extract withaferin a as a novel cytotoxic and synergistic agent against malignant gliomas. J Surg Res 165: 311, 2011. DOI: $10.1016 /$ j.jss.2010.11.352

10 Misra L, Lal P and Kumar D: Components of nutraceutical value in physalis minima. Prev Nutr Food Sci 11(1): 25-30, 2006. DOI: $10.3746 /$ jfn.2006.11.1.025

11 Dai T, Jiang W, Guo Z, Wang Z, Huang M, Zhong G, Liang C, Pei $X$ and Dai R: Studies on oral bioavailability and first-pass metabolism of withaferin a in rats using $\mathrm{lc}-\mathrm{ms} / \mathrm{ms}$ and q-trap. Biomed Chromatogr: e4573, 2019. PMID: 31062367. DOI: 10.1002/bmc.4573

12 Patil D, Gautam M, Mishra S, Karupothula S, Gairola S, Jadhav S, Pawar S and Patwardhan B: Determination of withaferin a and withanolide a in mice plasma using high-performance liquid chromatography-tandem mass spectrometry: Application to pharmacokinetics after oral administration of withania somnifera aqueous extract. J Pharm Biomed Anal 80: 203-212, 2013. PMID: 23584079.DOI: 10.1016/j.jpba.2013.03.001

13 Manoharan S, Panjamurthy K, Balakrishnan S, Vasudevan K and Vellaichamy L: Circadian time-dependent chemopreventive potential of withaferin-a in 7,12-dimethylbenz[a]anthraceneinduced oral carcinogenesis. Pharmacol Rep 61(4): 719-726, 2009. PMID: 19815955.

14 Chang E, Pohling C, Beygui N, Patel CB, Rosenberg J, Ha DH and Gambhir SS: Synergistic inhibition of glioma cell proliferation by withaferin a and tumor treating fields. J Neurooncol 134(2): 259268, 2017. PMID: 28681243. DOI: 10.1007/s11060-017-2534-5

15 Grogan PT, Sarkaria JN, Timmermann BN and Cohen MS: Oxidative cytotoxic agent withaferin a resensitizes temozolomideresistant glioblastomas via mgmt depletion and induces apoptosis through akt/mtor pathway inhibitory modulation. Invest New Drugs 32(4): 604-617, 2014. PMID: 24718901. DOI: 10.1007/s10637-0140084-7

16 de Bouard S, Herlin P, Christensen JG, Lemoisson E, Gauduchon P, Raymond E and Guillamo JS: Antiangiogenic and anti-invasive effects of sunitinib on experimental human glioblastoma. Neuro Oncol 9(4): 412-423, 2007. PMID: 17622648. DOI: $10.1215 / 15228517-2007-024$

17 Dimitropoulos K, Giannopoulou E, Argyriou AA, Zolota V, Petsas T, Tsiata E and Kalofonos HP: The effects of anti-vegfr and anti-egfr agents on glioma cell migration through implication of growth factors with integrins. Anticancer Res 30(12): 4987-4992, 2010. PMID: 21187479.

18 Golding SE, Rosenberg E, Valerie N, Hussaini I, Frigerio M, Cockcroft XF, Chong WY, Hummersone M, Rigoreau L, Menear KA, O'Connor MJ, Povirk LF, van Meter T and Valerie K: Improved atm kinase inhibitor ku-60019 radiosensitizes glioma cells, compromises insulin, akt and erk prosurvival signaling, and inhibits migration and invasion. Mol Cancer Ther 8(10): 2894-2902, 2009. PMID: 19808981. DOI: 10.1158/1535-7163.MCT-09-0519

19 Cenciarini M, Valentino M, Belia S, Sforna L, Rosa P, Ronchetti S, D'Adamo MC and Pessia M: Dexamethasone in glioblastoma multiforme therapy: Mechanisms and controversies. Front Mol Neurosci 12: 65, 2019. PMID: 30983966. DOI: 10.3389/fnmol. 2019.00065
20 Martinho O, Silva-Oliveira R, Miranda-Goncalves V, Clara C, Almeida JR, Carvalho AL, Barata JT and Reis RM: In vitro and in vivo analysis of rtk inhibitor efficacy and identification of its novel targets in glioblastomas. Transl Oncol 6(2): 187-196, 2013. PMID: 23544171. DOI: 10.1593/tlo.12400

21 Frolov A, Evans IM, Li N, Sidlauskas K, Paliashvili K, Lockwood N, Barrett A, Brandner S, Zachary IC and Frankel P: Imatinib and nilotinib increase glioblastoma cell invasion via abl-independent stimulation of p130cas and fak signalling. Sci Rep 6: 27378, 2016. PMID: 27293031. DOI: 10.1038/srep27378

22 Demuth T and Berens ME: Molecular mechanisms of glioma cell migration and invasion. J Neuro-Oncol 70(2): 217-228, 2004. PMID: 15674479. DOI: 10.1007/s11060-004-2751-6

23 Lamszus K, Kunkel P and Westphal M: Invasion as limitation to anti-angiogenic glioma therapy. Acta Neurochir Suppl 88: 169177, 2003. PMID: 14531575.

24 Bargagna-Mohan P, Hamza A, Kim YE, Khuan Abby Ho Y, Mor-Vaknin N, Wendschlag N, Liu J, Evans RM, Markovitz DM, Zhan CG, Kim KB and Mohan R: The tumor inhibitor and antiangiogenic agent withaferin a targets the intermediate filament protein vimentin. Chem Biol 14(6): 623-634, 2007. PMID: 17584610. DOI: 10.1016/j.chembiol.2007.04.010

25 Grogan PT, Sleder KD, Samadi AK, Zhang H, Timmermann BN and Cohen MS: Cytotoxicity of withaferin a in glioblastomas involves induction of an oxidative stress-mediated heat shock response while altering akt/mtor and mapk signaling pathways. Invest New Drugs 31(3): 545-557, 2013. PMID: 23129310. DOI: $10.1007 / \mathrm{s} 10637-012-9888-5$

26 Hebbar N, Wang C and Rangnekar VM: Mechanisms of apoptosis by the tumor suppressor par-4. J Cell Physiol 227(12): 3715-3721, 2012. PMID: 22552839. DOI: 10.1002/jcp.24098

27 Lee IC and Choi BY: Withaferin-a - a natural anticancer agent with pleitropic mechanisms of action. Int J Mol Sci 17(3): 290, 2016. PMID: 26959007. DOI: 10.3390/ijms 17030290

28 Zhang B, Shah S, Prince J, Walters W, Bregy A, Guo Y, Komatar RJ and Graham RM: Et-71the antitumor effects of withaferin a in glioblastoma stem cells. NeuroOncol 16(suppl 5): v94-v95, 2014. DOI: $10.1093 /$ neuonc/nou255.68

29 Yang H, Wang Y, Cheryan VT, Wu W, Cui CQ, Polin LA, Pass HI, Dou QP, Rishi AK and Wali A: Withaferin a inhibits the proteasome activity in mesothelioma in vitro and in vivo. PLoS One 7(8): e41214, 2012. PMID: 22912669. DOI: 10.1371/ journal.pone. 0041214
Received May 3, 2019

Revised June 3, 2019

Accepted June 19, 2019 